\title{
Learning English: A Study of English Novel Reading Camp
}

\author{
Hsiao-Fang Cheng ${ }^{1 *}$
}

${ }^{1}$ National United University, \#1 Lien-da, Kung-cheng Li, Miaoli 360, TAIWAN

*Corresponding Author: hfcheng@nuu.edu.tw

Citation: Cheng, H.-F. (2020). Learning English: A Study of English Novel Reading Camp. Mediterranean Journal of Social E Behavioral Research, 4(2), 31-34. https://doi.org/10.30935/mjosbr/9598

Note: This article was presented in ICOINE 2014 : 3rd International Conference on Interdisciplinary Research in Education, 29-31 October 2014, Milano, Italy.

\begin{abstract}
Reading is an active involvement and mutual interaction between the reader and the text. Many studies show that reading causes a dramatic improvement in writing and literacy development. Teachers who adopt children's novel in their teaching believe students can achieve higher levels of reading comprehension in critical thinking and experience the essence of reading for pleasure. To explore the effects of English novel reading on EFL learning, a five-day English Novel Reading Camp was held to help students familiarize with reading strategies and activities as well as reading for pleasure. A children's novel which provides topics for discussion was used. The participants were thirty-eight senior high school students from a high school in central Taiwan. Data gathered for analysis included their journal writing, survey, group discussions, and interview. This study found that more than ninety percent of the students thought they had learned a lot from this camp and would like to attend similar camps in the future. They found that reading English children's novel was not as difficult as they thought before. Finishing reading it, they felt an excellent sense of achievement that they had never had before in learning English. They stated that they not only gained more vocabulary, but also realized the value of life, the importance of family and friendship. They also experienced how to interact with the text, illustrate some plots, initiate questions, exchange ideas or negotiate with their peers. This camp helped them be involved in literature discussion for meaning making, connection, and critical thinking. It is hoped that the results of this study will provide ideas concerning literacy development and an alternative method for developing EFL student's English proficiency.
\end{abstract}

Keywords: children's English novel, critical thinking, reading for pleasure

Received: 11 Mar. 2020 • Revised: 10 Jun. 2020 Accepted: 09 Jul. 2020

\section{INTRODUCTION}

For many foreign language learners, reading is one of the most important skills to acquire linguistic features, develop proper communicative competence, and obtain new information and knowledge. Especially in higher education, most academic materials are written in English; therefore, the ability to read the written language at a reasonable rate and with good comprehension has become a must and key to success for most learners. Effective reading is critical. Grabe and Stoller (2002) state that learning to read does not mean learning rules and separate strategies and practicing them outside of the reading context. Like any other skill, reading from texts to synthesize information requires systematic training and practice (Brown, 2002). It is necessary to make it a habit to read in the target language on a regular basis and to set aside a certain amount of time every day to do some reading. Regular practice will improve the learner's ability to quickly and automatically recognize words. This, in turn, will lead to an improved reading rate. As learners read more quickly, they will find reading in a foreign language more pleasurable. As they advance, they will find that they can increase both the number of pages read and the difficulty of the materials they can handle. Flowerdew and Peacock (2001) also point out that reading extensively in academic English requires L2 learners to develop macro- and micro-skills. The macroskills include the ability to relate new information to background knowledge to form new schemata. Important micro-skills include recognizing logical relationships, definitions, generalizations, examples, explanations and predictions. All these abilities require lots of practice in reading which, in turn, is dependent on strong motivation being maintained.

Readers construct their own meaning by transacting with the text. Efficient and effective reading requires both top-down and bottom-up strategies functioning interactively (Rumelhart, 1980). Top-down processing aims at the making of predictions about the text based on prior experience or background knowledge. In the course of reading, predictions are checked and justified accordingly and finally confirmation or refutation of those predictions is made. Bottom-up processing focuses on decoding individual linguistic units and building 
textual meaning from the smallest units to the largest. Preexisting background knowledge and current predictions are modified according to the information encountered in the text. Comprehending a text is an interactive process between the reader's background knowledge and the text, not solely relying on one's linguistic knowledge (Carrell \& Eisterhold, 2000). A reader's failure to activate an appropriate schema during reading results in various degrees of non-comprehension (Carrell, 1984).

Reading is a powerful means of developing reading comprehension ability, writing style, lexical knowledge, grammatical competence and spelling (Krashen, 2002). Furthermore, it promotes cognitive development and lowers writing apprehension. Many studies show that extensive reading caused a dramatic improvement in writing (Cohen, 1999), vocabulary (Saragi, Nation, \& Meister, 1978), and spelling (Haggan, 1991). Those who read more make significant greater gains in reading comprehension and write better (Cohen, 1999). The study done by Ivey and Broaddus (2001) showed that sixth graders' favorite activities in their language arts class was free reading time. Research by Hayes and Ahrens (1988) suggests that comic books can serve as a conduit to heavier reading and teen romances may be ideal sources of comprehensible and interesting reading material for some acquirers of English as a foreign language (Cho and Krashen, 1995). Such kind of light reading causes a dramatic improvement in writing, spelling, vocabulary development and grammar (Krashen, 2004).

In many learning situations, learners must know where they are going and how they should get there. The ability to read English texts is not a natural phenomenon; it cannot be acquired suddenly and accidentally. It is a time-consuming process taking years and requiring patience, determination and systematic guidance. Anderson (1999) mentions that reading, an active involvement and mutual interaction between the reader and the text, is an essential skill for learners of English as a second/foreign language. When reading skills are strengthened, significant progress in academic areas is seen and success is achieved.

In Taiwan, the majority of students, having studied English as a subject at school for more than seven years, regard English as the main objective of learning instead of a medium for learning new knowledge and information. They focus on learning linguistic features in the hope of obtaining high scores in the college entrance exam. They have never learned to read for pleasure. Their efforts to read English texts meet with a decided lack of success, even though this has a prejudicial effect on their vocational or academic progress. Their first feelings of frustration are followed by a gradual loss of motivation and enthusiasm. Therefore, it is necessary to motivate students to read more and experience a sense of success in reading English. This English Novel Reading Camp was designed to promote extensive reading and reading for pleasure by introducing appropriate reading strategies. The structure of literature circles were adopted and modified to fit in the current situation. Traditionally, in literature circles, students can choose the novel they like to read and need a "role sheet", acting as questioner, connector, illustrator, word wizard and literature luminary. Due to time-constraint, they were not allowed to choose their own reading material; word wizard and literature luminary were not practiced during the camp. Reading strategies such as questioning, connecting, inferring, visualizing, determining importance, etc. as well as social skills like active listening, asking follow-up questions, disagreeing agreeably, negotiating with peers were introduced and practiced (Daniels, 2006). Reader's theater, a letter to the writer or one of the characters, teacher's observation and student's journals were adopted as assessment. Hopefully, participants will be motivated to do more voluntary reading thereafter.

\section{METHOD}

\section{Participants}

Thirty-eight high school students from a high school in central Taiwan participated in this study voluntarily. Twelve of them were in the third year and the rest were in the second year of high school. They had already learned English as a subject for more than seven years. They thought their English ability belonged to pre-intermediate level.

\section{The Reading Material-- Because of Winn-Dixie}

A children's English novel-Because of Winn-Dixie, written by Kate DeCarmilio was adopted as material. It is a touching story about a tenyear-old girl, Opal Buloni and her dog, Winn-Dixie. One summer day Opal went down to the local supermarket for some groceries and came home with the dog. It was because of Winn-Dixie that Opal got to meet the surprising people in town and started to make new friends. It was because of Winn-Dixie that she dared to ask her father ten questions about her mom, who left her when she was three. The key concept of this story is about family value and friendship.

\section{Procedures}

This camp lasted for five days. It provided students with opportunities to actively engage in the learning processes by making predictions, illustrating the most impressive part, asking questions, sharing ideas, and making a connection from text to self, text to text, or text to world. A pre-study survey concerning participant's attitude toward reading English and their reading strategies was conducted on the first day of the camp. Another post-study survey with regard to their perceptions of attending this camp and their inspiration was administered on the last day. They were required to finish reading five chapters a day before attending the class. In class appropriate reading strategies were introduced and practiced.

\section{RESULTS AND DISCUSSION}

\section{The Survey Results}

The pre-study survey showed that apart from the assigned reading passages, seventy percent of the participants had never read an English novel before. They regarded English as the main objective of learning instead of a medium for learning new knowledge and information. Therefore, they focused on learning individual words and linguistic features in the hope of earning high scores in the college entrance exam. They seldom devoted themselves to light or free voluntary reading, even though this has a prejudicial effect on their vocational or academic progress. The majority of them would repeat reading the parts they did not understand. Half of those who repeated reading improved their comprehension; however, the rest did not increase comprehension even though they read it the second or third time. It was possible that they had limited vocabulary or grammatical knowledge. Probably they did not know how to use the appropriate reading strategies to enhance comprehension. They felt very depressed and frustrated when they failed to recognize the words and comprehend the reading texts. They 
thought reading English novel was a great challenge, so they decided to attend the camp and hoped they could learn something new or different from this camp.

In response to what they had learned from the camp, more than ninety-two percent of the participants thought they had learned many new words, how to figure out the meaning from the context, and several reading strategies they had never used before. They enjoyed the story and reading every chapter of the novel. The language of the novel is neither too difficult nor too easy for them to read. By reading this novel they had achieved higher levels of reading comprehension in critical thinking and experienced the essence of reading for pleasure. This finding conforms to Daniel's (2006) claim that appropriate text facilitates success for learners. As the words within a book become comprehensible, their English proficiency develops (Krashen, 2002).

With reference to the benefits of learning reading strategies, more than eighty-six percent of the participants said they could visualize the picture of what they had read. In other words, a vivid picture would appear clearly in their mind during the reading processes. More than eighty percent of them said that they could connect what they had read to their own experience or life. Ninety percent of them said that based on the relevant clues, they could initiate questions, propose topics for discussion, connect to their life or experience. Eighty-eight percent of them said that through group discussion and negotiation, they comprehended the content better and more profoundly. Furthermore, they learned a lot of things they had never thought before from others apart from the content in the novel. Most important of all, they felt excited to join the camp and would like to attend similar camps in the future.

\section{Preferred Activities}

The purpose of this camp is to introduce reading strategies, such as questioning, connecting, inferring, visualizing, etc. In relation to the above strategies, they were asked to initiate questions, illustrate, discuss in small groups, read aloud, share quotes, write a letter to the writer or one of the characters, and keep journals. Among those activities, they liked illustration the most, group discussion and initiating questions the second; reader's theater and sharing ideas came the last.

Ninety percent of the participants said they enjoyed illustration the most. They stated that illustration reflected their understanding and helped them understand the content better. They tried to visualize or imagine in their head the vivid pictures of what they had read. While drawing it on the paper, every member contributed their imagination or understanding collaboratively. During the sharing period, they could see how each group visualized the written texts, compare their own illustration with others, and perceive the differences and similarities. After comparing and reviewing what they had done, they understood the meaning of the written texts in more depth. Team work, imagination, and creativity were keys to success in this stage.

The second activity they preferred was group discussion which substantially helped with comprehension. Due to tight class schedule and the emphasis of individual performance, group discussion is seldom employed in most high schools in Taiwan -- students tend to read on their own and seldom discuss their comprehension or incomprehension with their peers in class or after class. However, during the camp they were asked to discuss in small groups, run cooperatively by group members, so they felt less risk than in a wholeclass discussion. In addition to discussing linguistic features, they not only shared their experiences and perceptions with their group members but also learned something they had never thought of before from their peers. In most occasions, their peer's interpretation inspired them to think about the issue further or look at it from a different point of view. After discussion and negotiation they learned the connotation or the hidden meaning the writer wanted to convey and understood the content more profoundly. More importantly, they had what they failed to understand become comprehensible and they felt more willing to express and exchange ideas or viewpoints with others. They also found that initiating and answering questions among group members in which everyone is engaged and acting upon the subject matter is better than standard "whole-class discussions" where two or three students monopolize the conversation.

The third activity they valued was initiating questions. Since they started to learn English, they have practiced how to answer questions given by the teachers instead of initiating questions. They found it was interesting and fun to take the initiative to ask questions--they could ask what they did not understand or what they had already understood. Being able to ask appropriate questions, they needed to understand the deep meaning of the written texts. They found that it was more difficult to ask appropriate questions than to answer questions.

Of all the activities, reader's theater and sharing quotes were two activities most of them did not like. Even though they learned to imitate the intonation, the tone, the pitch, etc. of the designated character while doing reader's theater, they said they liked it the least. It was possible that they were shy to act out the dialogue because they did not know each other very well or they did not completely understand the content. As for sharing ideas, they were seldom trained to express their feelings verbally in public in Chinese, let alone in English. What's more, they seldom practiced speaking English in class even though they did a lot of reading and listening. If they were from the same class, they might be more willing to take the chance and try to act out or speak up.

\section{Perceptions}

When asked what inspiration they had had after reading Because of Winn-Dixie, all of them said that they had experienced a strong sense of achievement. Though they attended the camp voluntarily, at the beginning they were not confident of success. When they were told to read this novel, they thought they were unable to finish reading it because of their limited English ability. However, after using the introduced methods to read the first two chapters, they found it was not as difficult as they thought before. They found the story was so relevant to their own experiences that they were fascinated by it and curious about what might happen next. They continued reading one chapter after another. Finally they finished reading their first English novel. They felt so excited and proud of themselves. One student reflected that before attending the camp, she just read the surface meaning of the text without figuring out the hidden meaning. After training, she learned to guess the meaning from the context. She also found that reading English textbooks is not the only way of learning English. Reading a novel, exciting and rewarding, is a good alternative of learning a foreign language. She stated that she not only acquired more vocabulary, but also realized the value of life, the importance of family and friendship. She also experienced how to interact with the text, illustrate some plots, initiate questions, exchange ideas or negotiate with their peers. What a great success she had accomplished!

Apart from the perceptions participants mentioned, the researcher also found culture-specific effect of content background knowledge on 
reading comprehension, i.e., participant's interpretation of the written texts. For example, when they drew the picture of Gloria Dump, they thought her as an old Chinese woman, wearing Chinese hair style and clothing. It was obvious that they related the information from the text to already existing background knowledge, cultural-specific schema of an old lady. As the saying goes, "One picture is worth a thousand words." This finding suggests that illustrations may be particularly appropriate for students with minimal language skills and a good alternative measure of comprehension. It further reminds English teachers of pre-teaching a key concept which is culturally loaded.

\section{CONCLUSION}

One of the major goals of foreign language education is to encourage free voluntary and extensive reading. The most powerful way of encouraging students to read is to expose them to light reading, such as novel reading. Direct encouragement to read can work if reading material is interesting and comprehensible. It is certain that one positive reading experience can create a reader and play an important role in helping him/her progress to the level where he/she can read and understand the demanding texts. Drawing on what participants had narrated, they benefited a lot from attending this camp. First of all, they learned to use reading strategies, such as, illustration, group discussion, asking questions, etc. to enhance reading comprehension. Next, they learned how to interact with their peers and realized the importance and advantages of group discussion which was seldom used in their previous learning context. Then, they held positive attitudes toward reading English novels and decided to forge a good relationship with their friends and family members. Last but not the least, they learned a lot of new words and felt a strong sense of success they had never experienced before.

In conclusion, when participants are engaged in well-structured activities, both their comprehension and their attitudes toward reading improve. After attending this camp, they were motivated to be involved in literature discussion for meaning making, connection, and critical thinking. Novel reading is definitely one of appropriate methods for developing English proficiency and literacy.

\section{SUGGESTION AND IMPLICATION}

In this study, participants read a single author and found that the text became easier to comprehend after the first few pages. They finally finished reading the first English novel and felt a great sense of success. If they are motivated to read more novels written by different authors, their language proficiency and literacy will improve substantially. For foreign language learners, reading more is important whereas the guidance of English teachers is far more important.

\section{ACKNOWLEDGEMENTS}

I would like to extend my sincere gratitude to Professor Chiouhui Chou, who helped with the curriculum design and lecture. Grateful thanks are also due to the participants, in one way or another, contributed to the collection of the data.

\section{REFERENCES}

Anderson, N. (1999). Exploring Second Language Reading: Issues and Strategies. Boston, MA: Heinle \& Heinle Publishers.

Brown, H. D. (2002). Strategies for Success: A practical guide to learning English. New York: Addison Wesley Longman.

Carrel, P. L. (1984). Evidence of a formal schema in second language comprehension. Language Learning, 34(2), 87-112. https://doi.org/10.1111/j.1467-1770.1984.tb01005.x

Carrell, P. L. \& Eisterhold, J. C. (2000). Schema theory and ESL reading pedagogy. In P. L. Carrell, J. Devine, \& D. E. Eskey (Eds.), Interactive Approaches to Second Language Reading. (pp. 73-92). Cambridge: Cambridge University Press. https://doi.org/10.1017/ CBO9781139524513.010

Cho, K. S., \& Krashen, S. (1995). Becoming a dragon: Progress in English as a second language through narrow free voluntary reading. California Reader, 29, 9-10.

Cohen, K. (1999). Reluctant eighth grade readers enjoy sustained silent reading. California Reader, 33(1), 22-25.

Daniels, H. (2006). What's the next big thing with literature circles? Voices from the Middle, 13(4), 10-15.

DeCarmilio, K. (2004). Because of Winn-Dixie. London: Walker Books Ltd.

Flowerdew, J. \& Peacock, M. (2001). Research Perspectives on English for Academic Purposes. Cambridge: Cambridge University Press. https://doi.org/10.1017/CBO9781139524766

Grabe, W. G., \& Stoller, F. L. (2002). Teaching and Researching Reading. Harlow: Pearson Education Limited.

Haggan, M. (1991). Spelling errors in native Arabic-speaking English majors: A comparison between remedial students and fourth year students. System, 19, 45-61. https://doi.org/10.1016/0346251X(91)90007-C

Hayes, D., \& Ahrens, M. (1988). Vocabulary simplification for children: A special case of "motherese"? Journal of Child Language, 15, 395-410. https://doi.org/10.1017/S0305000900012411

Ivey, G., \& Broaddus, K. (2001). "Just plain reading": a survey of what makes students want to read in middle school classrooms. Reading Research Quarterly, 36(4), 350-377. https://doi.org/10.1598/ RRQ.36.4.2

Krashen, S. D. (2002). Explorations in Language Acquisition and Use: The Taipei Lectures. Taipei: Crane Publishing Co., Ltd.

Krashen, S. D. (2004). The Power of Reading: Insights from the research. Portsmouth: Heinemann.

Rumelhart, D. E. (1980). Schemata: the building blocks of cognition. In R.J. Spiro, B.C. Bruce, \& W. E. Brewer (Eds.), Theoretical Issues in Reading Comprehension. (pp. 33-58). Hillsdale, N.J.: Erlbaum. https://doi.org/10.4324/9781315107493-4

Saragi, Y., \& Nation, P., \& Meister, G. (1978). Vocabulary learning and reading. System, 6, 70-78. https://doi.org/10.1016/0346251X(78)90027-1 